\title{
BMJ Open Association between sexually transmitted disease and church membership. A retrospective cohort study of two Danish religious minorities
}

\author{
Alex Kappel Kørup, ${ }^{1}$ Lau Caspar Thygesen, ${ }^{2}$ René dePont Christensen, ${ }^{1}$ \\ Christoffer Johansen, ${ }^{3}$ Jens Søndergaard, ${ }^{1}$ Niels Christian Hvidt ${ }^{1}$
}

To cite: Kørup AK, Thygesen LC,

Christensen $\mathrm{R}$ deP, et al. Association between sexually transmitted disease and church membership. A retrospective cohort study of two Danish religious minorities. BMJ Open 2016;6:e010128.

doi:10.1136/bmjopen-2015010128

- Prepublication history and additional material is available. To view please visit the journal (http://dx.doi.org/ 10.1136/bmjopen-2015010128).

Received 28 September 2015 Revised 24 February 2016 Accepted 4 March 2016

CrossMark

\footnotetext{
${ }^{1}$ Research Unit of General Practice, University of Southern Denmark, Odense, Denmark

${ }^{2}$ National Institute of Public Health, Copenhagen,

Denmark

${ }^{3}$ Department of Oncology

Clinic, University of

Copenhagen, Copenhagen, Denmark
}

Correspondence to Dr Alex Kappel Kørup; akorup@health.sdu.dk

\section{ABSTRACT}

Objectives: Studies comprising Danish Seventh-day Adventists (SDAs) and Danish Baptists found that members have a lower risk of chronic diseases including cancer. Explanations have pointed to differences in lifestyle, but detailed aetiology has only been sparsely examined. Our objective was to investigate the incidence of sexually transmitted diseases (STDs) among Danish SDAs and Baptists as a proxy for cancers related to sexual behaviour.

Methods: We followed the Danish Cohort of Religious Societies from 1977 to 2009, and linked it with national registers of all inpatient and outpatient care contacts using the National Patient Register. We compared the incidence of syphilis, gonorrhoea and chlamydia among members of the cohort with the general population.

Results: The cohort comprised 3119 SDA females, 1856 SDA males, 2056 Baptist females and 1467 Baptist males. For the entire cohort, we expected a total of 32.4 events of STD, and observed only 9. Female SDAs and Baptists aged 20-39 years had significant lower incidence of chlamydia (both $p<0.001)$. Male SDAs and Baptists aged $20-39$ years also had significant lower incidence of chlamydia $(p<0.01$ and $p<0.05$, respectively). No SDA members were diagnosed with gonorrhoea, when 3.4 events were expected, which, according to Hanley's 'rule of three', is a significant difference. No SDA or Baptist was diagnosed with syphilis.

Conclusions: The cohort shows significant lower incidence of STD, most likely including human papillomavirus, which may partly explain the lower incidence of cancers of the cervix, rectum, anus, head and neck.

\section{INTRODUCTION}

Studies have shown associations between religious affiliation and higher lifetime expectancy and reduced risk of lifestyle diseases

\section{Strengths and limitations of this study}

- A large homogeneous cohort comprising 200000 person years was followed from 1977 to 2009.

- We have complete follow-up data for all individuals included due to the Danish tradition of public healthcare for everyone and through nationwide registers.

- We did not have access to records from general practice.

- Only 26 of the 46 Baptist communities participated in the study, making that part of the cohort vulnerable to selection bias.

- We were not able to measure actual religious practice in the cohort but only church membership.

such as cardiovascular ailments, ${ }^{1}$ certain types of cancer $^{2}{ }^{3}$ and mental illness. ${ }^{4} 5$ Studies of the Danish Cohort of Religious Societies $^{6}$ have described a lower incidence of cancer in the oral cavity, lung, oesophagus, stomach, liver, rectum/anus and cervix, ${ }^{2}$ among Danish Seventh-Day Adventists (SDAs) and Baptists. For cervical cancer, Thygesen $e t a l^{2}$ showed a relative risk (standardised incidence ratio, SIR) of 0.66 (0.4789) for SDAs and $0.22 \quad(0.09-0.46)$ for Baptists in the cohort. SDAs and Baptists are characterised by abstaining from alcohol and tobacco. A substantial body of research has documented and highlighted the link between religion and sexual preferences, including religious recommendations for premarital and extramarital sexual abstinence. Also, spirituality and belonging to a religious community are associated with later sexual debut, condom use and fewer lifetime sexual 
partners. $^{7-12}$ However, actual incidence of sexually transmitted disease (STD) has, to the best of our knowledge, not previously been studied in a large cohort of religious individuals.

Several of the cancer types that showed less incidence in the Danish Cohort of Religious Societies are caused, mainly or in part, by the sexually transmitted high-risk human papillomaviruses (HPVs). HPV tests including 16 types of HPV are positive in 5-40\% of asymptomatic women during their reproductive age, and up to $75 \%$ of adults are infected during their lifetime, ${ }^{13}{ }^{14}$ although there are large regional variances. The risk of HPV infections rises with increasing number of sexual partners, younger age at sexual debut and recent change of partner. ${ }^{13} 1516 \mathrm{HPV}$ and chlamydia infection are most likely associated, and the latter is now believed to play an important role as a cofactor in the development of invasive cervical cancer. ${ }^{17}$

Hence, we hypothesise that the religious societies in the cohort have a lower incidence of STD including HPV, and also that a lower incidence of HPV can help explain the lower cancer incidence previously found in the religious societies in the Danish Cohort of Religious Societies.

\section{Study aim}

We aim to test whether: (1) the religious societies in the cohort have a lower incidence of STD and, therefore, a lower incidence of HPV, and (2) the lower cancer incidence found in the religious societies in the Danish Cohort of Religious Societies-attributed by lifestyle factors-is, in part, mediated by a lower burden of HPV infections.

\section{MATERIAL AND METHODS}

Our study is based on the cohort from 'The Danish Religious Societies Health Study'. ${ }^{6}$ The headquarters of

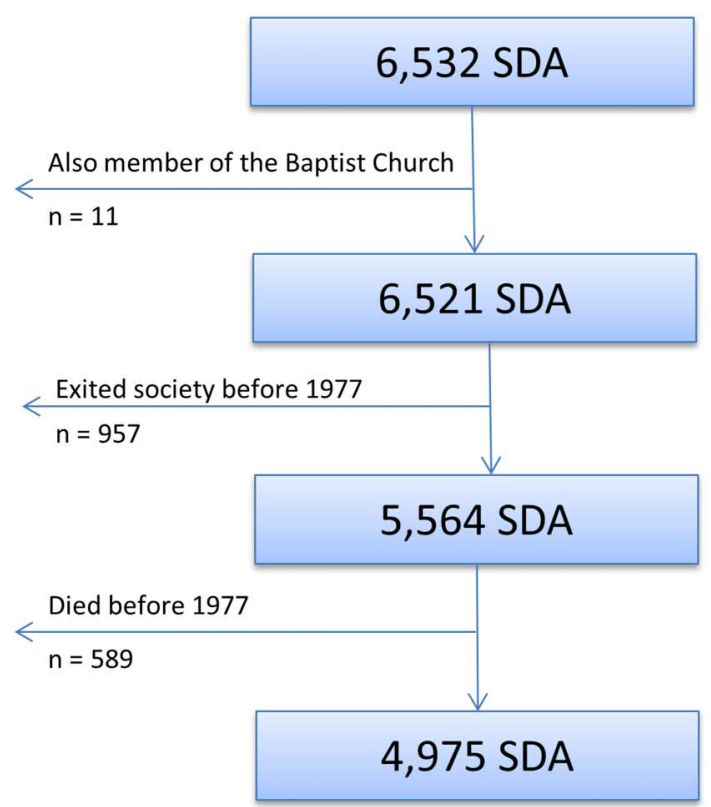

the Danish SDAs has been registering their members in a central index card register from 1920 to 2005, and from then on electronically. In total, 20057 index cards have been thoroughly analysed, excluding cards belonging to members who were not born in Denmark $(\mathrm{n}=1997)$, had invalid dates of baptism/becoming a member or birth $(\mathrm{n}=690)$, duplicates $(\mathrm{n}=6740)$, died before $1943(\mathrm{n}=355)$, were not identifiable from the index card $(n=2304)$, or those not matched in the Danish Civil Registration System, where all Danes are registered with a unique personal ID $(\mathrm{n}=1381)$.

In order to collect information about the Baptists, all of the 46 existing Baptist communities were contacted and invited to participate in the cohort-26 communities accepted. A total of 6042 index cards were analysed, excluding those who died before 1943 ( $\mathrm{n}=92)$, duplicates $(n=1724)$, those not identified on the index card $(n=233)$ and those who could not be matched in the Danish Civil Registration System ( $\mathrm{n}=273)$.

In sum, the original cohort is a collection of 11874 members of the SDA Church $(n=6532)$ and Baptist Church $(n=3980)$ in Denmark, who were either a previous or current member of one of the societies during the observation period 1943-2007.

For our present study, we had to narrow the original cohort further, excluding SDAs who were members of both the Baptist Church and SDA Church $(n=11)$, those who discontinued their membership before 1977 $(\mathrm{n}=957)$ and those who died before $1977(\mathrm{n}=589)$. In the Baptist cohort, 11 members who were also members of the SDA church were excluded, as were 260 unidentifiable members and 186 who died before 1977 (figure 1). Individuals were followed from the day they were registered as member of one of the societies until end of

Figure 1 Cohort exclusion. SDA, Seventh-day Adventist. 
follow-up, 31 December 2009, date of leaving the society, or date of death, whichever came first (table 1).

In Denmark, all residents are assigned a unique personal identification number in the Danish Civil Registration System, allowing linkage for each member to other national registers. Since 1977, all inpatient healthcare contacts have been continuously registered in the Danish National Patient Register, and, from 1995, all outpatient and emergency contacts have been included. ${ }^{18}$ Until 1993, diseases were registered using International Classification of Diseases, 8 (ICD-8) codes, and from 1994 onwards, ICD-10 codes were used. From the Danish National Patient Register, we extracted individual first-time healthcare contacts due to primary and secondary syphilis infections, gonorrhoea or chlamydia related disease (codes 091-099 in ICD-8 and A51-A56 in ICD-10). If an individual had multiple contacts due to the same disease, only the first event was used. For comparison, we made an equal extraction for the entire Danish population of first-time healthcare contacts due to the same STDs (table 2).

The study was approved by the Danish Data Protection Agency (file number 2014-41-2709).

\section{Statistical analysis}

To calculate expected events in the cohort, we first calculated the age-specific and gender-specific incidence rates for each of gonorrhoea, syphilis and chlamydia related disease in the Danish population, using data from the Danish National Patient Register. For both, SDAs and Baptists, we counted age-specific and genderspecific person years in the cohort, using this value to calculate the expected number of STD diagnosing codes for each group. Differences in expected and observed cases were analysed using Pearson $\chi^{2}$ test and $p$ values were adjusted with Fisher's Exact Test.

Our design creates multiple zero observations in the age groups, and we have thus chosen to use Hanley's 'rule of 3' to estimate the significance of these findings. ${ }^{19} 20$ This rule is applicable when zero events are observed in a finite set of more than 30 individuals,

\begin{tabular}{|c|c|c|c|c|}
\hline & \multicolumn{2}{|c|}{$\begin{array}{l}\text { Seventh-day } \\
\text { Adventists }\end{array}$} & \multicolumn{2}{|l|}{ Baptists } \\
\hline & Women & Men & Women & Men \\
\hline Included persons, $\mathrm{n}$ & 3119 & 1856 & 2056 & 1467 \\
\hline $\begin{array}{l}\text { Person years of } \\
\text { follow-up, mean }\end{array}$ & 23.0 & 24.7 & 23.9 & 23.2 \\
\hline $\begin{array}{l}\text { Person years of } \\
\text { follow-up, sum }\end{array}$ & 71600 & 45907 & 49054 & 33980 \\
\hline $\begin{array}{l}\text { Age at } \\
\text { membership, mean }\end{array}$ & 32.2 & 26.4 & 19.7 & 20.5 \\
\hline $\begin{array}{l}\text { Age at } \\
\text { membership, } \\
\text { median }\end{array}$ & 24.1 & 18.7 & 16.5 & 17.5 \\
\hline
\end{tabular}

\begin{tabular}{|c|c|c|c|}
\hline Gender & Age group & Observed ${ }^{*}$ & $\begin{array}{l}\text { Incidence per } \\
100000 \text { person } \\
\text { years }\end{array}$ \\
\hline \multicolumn{4}{|c|}{ Chlamydia and related } \\
\hline \multirow[t]{5}{*}{ Male } & $0-19$ & 715 & 3.2 \\
\hline & 20-39 & 6058 & 23.8 \\
\hline & $40-59$ & 915 & 4.1 \\
\hline & $60-79$ & 227 & 1.7 \\
\hline & $80-$ & 26 & 1.2 \\
\hline \multirow[t]{5}{*}{ Female } & $0-19$ & 4979 & 23.4 \\
\hline & 20-39 & 10788 & 44.0 \\
\hline & $40-59$ & 1325 & 6.0 \\
\hline & $60-79$ & 213 & 1.4 \\
\hline & $80-$ & 27 & 0.7 \\
\hline \multicolumn{4}{|c|}{ Gonorrhoea } \\
\hline \multirow[t]{5}{*}{ Male } & $0-19$ & 179 & 0.8 \\
\hline & 20-39 & 973 & 3.8 \\
\hline & $40-59$ & 271 & 1.2 \\
\hline & $60-79$ & 61 & 0.5 \\
\hline & $80-$ & 16 & 0.8 \\
\hline \multirow[t]{5}{*}{ Female } & $0-19$ & 1783 & 8.4 \\
\hline & 20-39 & 2922 & 11.9 \\
\hline & $40-59$ & 168 & 0.8 \\
\hline & $60-79$ & 30 & 0.2 \\
\hline & $80-$ & 12 & 0.3 \\
\hline \multicolumn{4}{|l|}{ Syphilis } \\
\hline \multirow[t]{5}{*}{ Male } & $0-19$ & 76 & 0.3 \\
\hline & 20-39 & 676 & 2.7 \\
\hline & $40-59$ & 476 & 2.1 \\
\hline & $60-79$ & 340 & 2.6 \\
\hline & $80-$ & 54 & 2.6 \\
\hline \multirow[t]{5}{*}{ Female } & $0-19$ & 91 & 0.4 \\
\hline & 20-39 & 469 & 1.9 \\
\hline & $40-59$ & 201 & 0.9 \\
\hline & $60-79$ & 268 & 1.7 \\
\hline & $80-$ & 66 & 1.6 \\
\hline
\end{tabular}

*Incidences of first-time registered sexually transmitted disease-diagnosis per individual in the Danish population in the period 1977-2009.

determining an upper boundary of $95 \%$ CI using the formula CI $95 \%$ (upper) $=3 / \mathrm{n}$. If we thus expect more than 3 events in the set, the proportion exceeds the upper confidence interval (expected $/ \mathrm{n}>3 / \mathrm{n}$ ), and we can conclude with $95 \%$ confidence that the lack of observations is significant.

All data management and statistical analysis were conducted using Stata V.13.1.

\section{RESULTS}

The study comprised 3119 females and 1856 males belonging to the SDA Church, and 2056 females and 1467 males belonging to the Baptist Church. For SDAs, the mean age at membership was 32.2 years for females and 26.4 for males. The ages at membership for Baptists were lower than those of SDAs, with 19.7 years for 
Table 3 Follow-up risk years in the cohort and control group (Danish population)

\begin{tabular}{|c|c|c|c|c|c|c|c|}
\hline \multirow[b]{2}{*}{ Gender } & \multirow[b]{2}{*}{ Age group } & \multicolumn{2}{|l|}{ SDAs } & \multicolumn{2}{|l|}{ Baptists } & \multicolumn{2}{|l|}{ Danish population } \\
\hline & & Individuals (n) & Risk years & Individuals (n) & Risk years & Individuals (mean) & Risk years \\
\hline \multirow[t]{5}{*}{ Male } & $0-19$ & 400 & 4319 & 229 & 941 & 676771 & 22333447 \\
\hline & $20-39$ & 965 & 12142 & 742 & 8805 & 772929 & 25506646 \\
\hline & $40-59$ & 1152 & 14624 & 998 & 12860 & 672779 & 22201699 \\
\hline & $60-79$ & 1048 & 11627 & 868 & 9726 & 398764 & 13159216 \\
\hline & $80-$ & 495 & 3331 & 302 & 1746 & 63665 & 2100954 \\
\hline \multirow[t]{5}{*}{ Female } & $0-19$ & 534 & 5561 & 326 & 1444 & 645098 & 21288240 \\
\hline & 20-39 & 1270 & 15787 & 982 & 11619 & 742193 & 24492366 \\
\hline & $40-59$ & 1605 & 19797 & 1339 & 17619 & 666383 & 21990638 \\
\hline & $60-79$ & 1908 & 21041 & 1232 & 14484 & 471623 & 15563571 \\
\hline & $80-$ & 1282 & 9652 & 556 & 4032 & 124896 & 4121568 \\
\hline Sum & & $4975^{\star}$ & & $3523^{*}$ & & 5235101 & 172758343 \\
\hline
\end{tabular}

${ }^{*}$ Note that individuals may have been observed over more than one age group and can figure in up to three age groups, hence the total number of individuals does not equal the sum of individuals counted in the age groups.

SDAs, Seventh-day Adventists.

females and 20.5 years for males. The members were followed for a total of 200541 person years (table 1). Risk years were counted for each age group in both, the cohort and the Danish population (table 3).

Table 1 shows that, in the Danish population, the majority of STD is found in the age groups below 40 years. For all three disease groups, for both genders, the age group 20-39 years is carrying the highest burden of STD. Chlamydia and gonorrhoea are diagnosed much more often in females aged 20-39 years than in males (44.0 vs 23.0 and 11.9 vs 3.8, respectively). This does not seem to be the case with syphilis, where the incidence of males is 2.7 vs 1.9 in females (table 2).

We followed the SDAs for a total of 117507 person years, and only two of the members were diagnosed with chlamydia-related diseases ( 1 male and 1 female aged between 20 and 39 years). No cases of gonorrhoea or syphilis were found in the SDA cohort. We expected 2.9 events of chlamydia in the male group, and the difference is significant at $\mathrm{p}<0.01$ (Fisher), $\chi^{2}=5.69$ (Pearson). We expected seven cases in the female age group, which also is statistically significant at $\mathrm{p}<0.001, \chi^{2}=16.78$. For chlamydia infections we calculated a SIR of 0.26 (0.01 to 1.47) for all male SDAs and $0.1(0.00$ to 0.56$)$ for all female SDAs (see web only table 1 ).

We followed the Baptists for a total of 83034 person years, and five were diagnosed with either gonorrhoea or chlamydia related disease. No Baptist was diagnosed with syphilis. In the age group 20-39 years, a single male and a single female were diagnosed with chlamydia-related disease. The expected numbers were 2.1 for males and 5.1 for females. These differences are significant at $\mathrm{p}<0.05$ (Fisher), $\chi^{2}=4.02$ and $\mathrm{p}<0.001$ (Fisher), $\chi^{2}=12.54$, respectively. Three females aged 40-59 years were diagnosed with chlamydia, where we expected only 1.1 events, but the finding did not prove statistically significant. Also diagnosed with chlamydia was a single female in the 60-79 years age group, where we expected 0.2 cases. This also is not a significant finding. For the chlamydia infections, we calculated a SIR of 0.36 (0.01 to 1.99) for all male Baptists and 0.75 (0.24 to 1.74) for all female Baptists. A single Baptist female in the 20-39 years age group was diagnosed with gonorrhoea, which equalled the expected 1.4 (see web only table 2 ).

None of the zero observations in the distinct age groups for either SDAs or Baptists were significant at a 95\% confidence level, using Hanley's 'rule of three', since this requires at least three expected cases, whereas none were found. But looking at expected cases of gonorrhoea for SDAs as a single unit, we would expect a total of 3.4 cases, which in fact makes it significantly unlikely that we would not find a single case of gonorrhoea in the SDA cohort.

\section{DISCUSSION}

In this study, we find lower incidences of STD in members of the Danish SDAs Church and Danish Baptist Church compared with the background population.

Several studies have described a negative relationship between religiosity and risky sexual behaviour, which may very well explain the lower incidence of STD and lifestyle as the most plausible explanation, ${ }^{7-11}{ }^{21}$ though none of the studies we found highlighted STD as a dependent variable. These studies are prone to limitations due to samples that are often small, nonrepresentative, and typically homogeneous with regard to economic and racial/ethnic representation. Rostosky et $a l^{11}$ contributed with a systematic review of the literature on the impact of religiosity on adolescent sexual behaviour and found that many questions remained unanswered, albeit the author points to evidence that religiosity does delay sexual debut.

Studies of actual STD as a dependent variable among religious communities in developed countries are sparse in the literature. Gray ${ }^{22}$ showed a negative association between Islam and the prevalence of HIV infections in 
the sub-Saharan African countries, which is in line with our findings. However, an Indian case-control study of 322 outpatients at a skin and venereal disease department did not find religion (Hinduism) to predict the cases. ${ }^{23}$

We also hypothesised that STD incidence is positively related to cancer incidence in the cohort, providing explanation for the lower incidence found earlier. ${ }^{2}$ The carcinogenic effect of HPV is described thoroughly in the literature. Since HPV is rarely diagnosed due to its primarily asymptomatic course, in neither our cohort nor in the Danish population were we able to measure the incidence of the actual infections. Using diseases that have a similar pattern of spread and cause is therefore a good proxy. Chlamydia infections are known to have a fairly asymptomatic cause, and are by some named a 'silent epidemic'. Glasier $e t a l^{4}$ describe the factor of riskier sexual behaviour for STD with severe symptoms for the transmission to be maintained. As infections with chlamydia and HPV are fairly asymptomatic, it may indicate that transmission is very sensitive to increases in risky sexual behaviour, and hence has a similar pattern of spread. Mainly, HPV types 16 and 18 are considered carcinogenic, but several other types are suspected to be involved in cancers as well. ${ }^{14}$ Practically all cases of cervix cancer, ${ }^{25}$ approximately $5-20 \%$ of all cancers of the head and neck, ${ }^{26}$ and approximately 80 $90 \%$ of anal cancers in men, ${ }^{27} 28$ are caused by HPV. An estimated $5.2 \%$ of the total cancer burden in the world is caused by HPV, 2.2\% in developed countries and $7.7 \%$ in developing countries. ${ }^{28}$

The lack of healthcare contacts due to STD in the cohort may, therefore, very well indicate a lower burden of HPV and, in the end, a lower risk of HPV-related cancers.

We find it interesting that the association between religion and sexual behaviour has only been the object of limited investigation, since social scientists already, back to Durkheim, proposed social influence and control theories for the association in what Wallace and Williams ${ }^{29}$ define as an overall 'socialisation influence framework' in which religion is one of the major social forces.

\section{Strengths}

Our study is strengthened by our large cohort and the fact that we have complete follow-up data for all individuals included. All Danes are registered in a central national database with a unique ID used for ensuring the identification of the individuals in the cohort.

The information about diagnosis codes was gathered from national registers that, since 1977, have been continuously updated by public as well as private hospitals in Denmark. This made it possible to extract exact information of public healthcare contacts for the entire Danish population for determining the population incidence rates. All data were standardised into age groups and incidence rates calculated based on person years to make comparison possible. Denmark has a healthcare system covering all Danish residents, making sure that economics or social class is not a factor limiting access to public healthcare facilities.

\section{Limitations}

The diagnosis codes we extracted from the national register include healthcare contacts in private and public hospitals and other public healthcare facilities in Denmark. We do not, however, have access to records from general practice. The vast majority of STD diagnostics and treatment is located at primary care/general practices, but the pattern of health seeking in general practice is probably similar for religious and non-religious Danes. If cohort individuals were more prone to avoid seeking help for sexually transmitted infections, we would expect STD to increase in the cohort due to untreated infections, which does not seem to be the case.

Only 26 of the 46 Baptist communities participated in the study, making that part of the cohort vulnerable to selection bias. We have not been able to control for potential differences in lifestyle factors and sexual behaviour compared with the Baptist communities that declined to participate.

Furthermore, we only had access to church membership and not the actual religious practice of the cohort members, hence their devoutness and adherence to religious practice may differ. Reasons to seek membership in minority church communities are many, and are affected by psychological, social and cultural forces, which may differ in non-Danish settings. This weakens the external validity of the study and must be taken into consideration when interpreting the results. However, previous research indicates that minority churches such as those in the cohort generally have higher rates of practice and religious vigour than the national Church of Denmark (Evangelical Lutheran Church). ${ }^{6}$

\section{FUTURE RESEARCH}

Further and more rigorous studies are needed to better understand the aetiology of the health benefits of the cohort in the Danish Religious Societies Health Study. It would, for instance, be interesting to measure the actual religious behaviour of the members and see how it correlates to the above findings.

Contributors AKK acted as the primary investigator; and contributed to the study design; data management, analysis and interpretation; and manuscript witting. LCT took part in the acquisition of data and critical revision of the manuscript. RdC participated in the analysis and interpretation of data, and critical revision of the manuscript. CJ and JS were responsible for the critical revision of the manuscript. $\mathrm{NCH}$ contributed to the study conception and design and critical revision of the manuscript.

Funding This work was supported by a grant from the 'Religion in the 21st Century' programme at the University of Copenhagen and grants from the Danish Cancer Society.

Disclaimer The funding organisations had no influence on the design and conduct of the study; collection, management, analysis and interpretation of the data; and preparation, review and approval of the manuscript.

Competing interests None declared. 
Ethics approval Danish Data Protection Agency.

Provenance and peer review Not commissioned; externally peer reviewed.

Data sharing statement For enquiries about the raw data used in this study please send an email to the corresponding author.

Open Access This is an Open Access article distributed in accordance with the Creative Commons Attribution Non Commercial (CC BY-NC 4.0) license, which permits others to distribute, remix, adapt, build upon this work noncommercially, and license their derivative works on different terms, provided the original work is properly cited and the use is non-commercial. See: http:// creativecommons.org/licenses/by-nc/4.0/

\section{REFERENCES}

1. Christiansen NS, Schmidt AW, Johansen C, et al. Risk for cardiovascular disease among Seventh-day Adventists and Baptists in Denmark, 1977-2009. Int J Cardiol 2015;185:133-5.

2. Thygesen LC, Hvidt NC, Hansen HP, et al. Cancer incidence among Danish Seventh-day Adventists and Baptists. Cancer Epidemiol 2012;36:513-18.

3. Wallace JM, Forman TA. Religion's role in promoting health and reducing risk among American youth. Health Educ Behav 1998;25:721-41.

4. Bonelli RM, Koenig HG. Mental disorders, religion and spirituality 1990 to 2010: a systematic evidence-based review. J Relig Health 2013;52:657-73.

5. Thygesen LC, Dalton SO, Johansen C, et al. Psychiatric disease incidence among Danish Seventh-day Adventists and Baptists. Soc Psychiatry Psychiatr Epidemiol 2013;48:1583-90.

6. Thygesen LC, Hvidt NC, Juel K, et al. The Danish Religious Societies Health Study. Int J Epidemiol 2012;41:1248-55.

7. Folkman S, Chesney MA, Pollack L, et al. Stress, coping, and high-risk sexual behavior. Health Psychol 1992;11:218-22.

8. Holder DW, DuRant RH, Harris TL, et al. The association between adolescent spirituality and voluntary sexual activity. J Adolesc Health 2000;26:295-302.

9. McCree $\mathrm{DH}$, Wingood GM, DiClemente $\mathrm{R}$, et al. Religiosity and risky sexual behavior in African-American adolescent females. J Adolesc Health 2003;33:2-8.

10. Poulson RL, Eppler MA, Satterwhite TN, et al. Alcohol consumption, strength of religious beliefs, and risky sexual behavior in college students. J Am Coll Health 1998;46:227-32.

11. Rostosky SS, Wilcox BL, Wright MLC, et al. The impact of religiosity on adolescent sexual behavior: a review of the evidence. J Adolesc Res 2004:19:677-97.
12. Lefkowitz ES, Gillen MM, Shearer CL, et al. Religiosity, sexual behaviors, and sexual attitudes during emerging adulthood. J Sex Res 2004;41:150-9.

13. Burchell AN, Richardson $\mathrm{H}$, Mahmud SM, et al. Modeling the sexual transmissibility of human papillomavirus infection using stochastic computer simulation and empirical data from a cohort study of young women in Montreal, Canada. Am J Epidemiol 2006;163:534-43.

14. IARC Working Group on the Evaluation of Carcinogenic Risks to Humans. Human papillomaviruses. IARC Monogr Eval Carcinog Risks Hum 2007;90:1-636.

15. Winer RL, Lee SK, Hughes JP, et al. Genital human papillomavirus infection: incidence and risk factors in a cohort of female university students. Am J Epidemiol 2003;157:218-26.

16. Sellors JW, Karwalajtys TL, Kaczorowski J, et al. Incidence, clearance and predictors of human papillomavirus infection in women. CMAJ 2003;168:421-5.

17. Silva J, Cerqueira F, Medeiros R. Chlamydia trachomatis infection: implications for HPV status and cervical cancer. Arch Gynecol Obstet 2014;289:715-23.

18. Lynge E, Sandegaard JL, Rebolj M. The Danish National Patient Register. Scand J Public Health 2011;39(7 Suppl):30-3.

19. Eypasch E, Lefering R, Kum CK, et al. Probability of adverse events that have not yet occurred: a statistical reminder. $B M J$ 1995;311:619-20.

20. Hanley JA, Lippman-Hand A. If nothing goes wrong, is everything all right? Interpreting zero numerators. JAMA 1983;249:1743-5.

21. Hoff A, Johannessen-Henry CT, Ross L, et al. Religion and reduced cancer risk: what is the explanation? A review. Eur $\mathrm{J}$ Cancer 2008;44:2573-9.

22. Gray PB. HIV and Islam: is HIV prevalence lower among Muslims? Soc Sci Med 2004:58:1751-6.

23. Shendre MC, Tiwari RR. Social risk factors for sexually transmitted diseases. Indian J Dermatol Venereol Leprol 2002;68:25-7.

24. Glasier A, Gülmezoglu AM, Schmid GP, et al. Sexual and reproductive health: a matter of life and death. Lancet 2006;368:1595-607.

25. Schiffman M, Castle PE, Jeronimo J, et al. Human papillomavirus and cervical cancer. Lancet 2007;370:890-907.

26. Zaravinos A. An updated overview of HPV-associated head and neck carcinomas. Oncotarget 2014;5:3956-69.

27. Kiellberg Larsen H, Kofoed K, Sand C. [The disease burden of human papillomavirus in men is substantial and can potentially be prevented]. Ugeskr Laeger 2013;175:349-53.

28. Parkin DM, Bray F. Chapter 2: The burden of HPV-related cancers Vaccine 2006;24(Suppl 3):S3/11-25.

29. Wallace JM, Williams DR. Religion and adolescent health-compromising behavior. In: Schulenberg J, Maggs JL, Hurrelmann K, eds. Health risks and developmental transitions during adolescence. UK: Cambridge University Press, 1997: 444-68. 